\title{
A Study on the Removal of Fluorescent Whitening Agent by Pretreatment Ozone Oxidation for MBR Process Application
}

\author{
Dong-Hoon Shin ${ }^{1}$, Jang-Seung Choi ${ }^{1}$, Seung-Han Ryu ${ }^{1}$, Sang-Hun Lee ${ }^{1}$, Won-Sik Shin ${ }^{2}$, Min-Soo Park \\ ${ }^{3}$, Jin-Ho $\mathrm{Kim}^{3}$, Jae-Eun Heo ${ }^{4, *}$ \\ ${ }^{1}$ Korea Dyeing and Finishing Technology Institude(DYETEC), Daegu, Republic of Korea \\ ${ }^{2}$ Department of Environmental Engineering, Kyungpook National University, Daegu, Republic of Korea \\ ${ }^{3}$ Econity Co. Ltd., Yongin, Republic of Korea \\ ${ }^{4}$ Ecoplus Co. Ltd., Cheonan, Republic of Korea \\ * Corresponding author: Tel.: +82 41 5223903. E-mail: kmuweb@gmail.com
}

\begin{abstract}
In this study, ozone oxidation experiment was carried out for the removal of fluorescent whitening agent which is widely used in textile dyeing and paper industry. The stilbene fluorescent whitening agent has been industrialized since the earliest, and the amount of current production is the highest. Due to the characteristics of the fluorescent whitening agent that cannot be removed by conventional wastewater treatment methods, the fluorescent whitening agent in wastewater treatment has difficulty in using as recycled water in the process. Pre-treatment ozone oxidation experiment was conducted prior to the introduction of Membrane Bio Reactor (MBR) treatment process by converting biodegradable materials into biodegradable materials. The removal efficiencies of fluorescent whitening agents, a diaminostilbene disulfonic acid derivative by ozone oxidation were evaluated by $\mathrm{UV}_{254} \mathrm{Scan}_{\text {, }}$ COD, T-N and color using a synthetic wastewater sample $(\mathrm{COD}=433.0 \mathrm{mg} / \ell)$ and paper and paper mill wastewater $(\mathrm{COD}=157.2 \mathrm{mg} / \ell)$.
\end{abstract}

Keywords: diaminostilbene disulfonic acid; paper and paper mill; textile wastewater; fluorescent whitening agents; ozone oxidation

\section{Introduction}

The fluorescent whitening dye and fluorescent whitening agent, which are widely used in the fiber dyeing industry and the paper-mill industry, make the product look white and removes the yellow discoloration, and they have been used on consumables such as paper, detergent, hygiene product, fiber, plastic, paint, and etc. The fiber industry takes up around $6 \%$ of all the wastewater discharge companies, and the wastewater discharge takes up around $11.8 \%$ in South Korea. However, the BOD pollution load takes up around $22.9 \%$ where it affects the public waters significantly. For the paper-mill industry, the paper-mill industry related companies take up around $0.9 \%$ of the total wastewater discharge companies as of 2013, but the wastewater discharge takes up around 14.2\% and the BOD pollution load takes up $11.7 \%$ of the total amount where it can be said to give significant influence to the public waters[1].

The fiber dyeing industry and the paper-mill industry are expected to receive limitations to the supply of industrial water needed for general operation of the industry, and measures are being requested on this. For the influence on the environment of fluorescent whitening dye and fluorescent whitening agent, it is reported that they are not decomposed well and that there is possibility of remains. However, it is evaluated to not be significantly influenced since the concentrations of the river and lake are not that high. 
On the other hand, the interest on the exposure of fluorescent whitening dye and fluorescent whitening agent has been increasing since the mid-1990s[2]. Fluorescent whitening agent absorbs ultraviolet light $(330 \sim 380 \mathrm{~nm})$ and is a type of a dye as a chemical substance with affinity on fiber and paper that emits fluorescence in short wavelength $(400 \sim 450 \mathrm{~nm})$ of the visible region. Fluorescent pigments and fluorescent whitening agents use oxidation and reducing agents to make the textiles (fiber, paper, pulp, and etc.) white. The fluorescent whitening agent treatment is executed because the small portion of yellowish brown cannot be completely removed in this kind of bleach[3,4]. The characteristic of the chemical structure of the fluorescent whitening agent is that it has double bond and has flat structure in general with electron-releasing power. It also has strong electron-aspirator such as $-\mathrm{NO}_{2},-\mathrm{N}=\mathrm{N}-$. The affiliation of the fluorescent whitening dye and fluorescent whitening agent applied according to the chemical characteristic of the fiber can be classified as stilbene fluorescent whitening agent, coumarine fluorescent whitening agent, oxazole fluorescent whitening agent, and napthal amide fluorescent whitening agent. The use can be classified according to the type of fiber. Stilbene fluorescent whitening agent has been commercialized since long ago and industrial output is the greatest among the aforementioned. The representative stilbene fluorescent whitening agent is the bis (triazinylamino) stilbestrol acid derivative or bis-triphenyl derivative. Most soluble fluorescent whitening agent substances are stilbene derivates and 4,4'-diaminostilbene-2,2'-disulphonic acid 의 bistriazinyl derivative are important substances[5].

The cellulose fluorescent whitening agent mostly uses diaminostilbene disulfonic acid derivative. The chemical structure is as shown in Figure 1. For the textiles, it is used in cotton, linen, rayon, bemberg, and etc. There are different kinds of affinity on the cellulose. It is also used for paper and pulp and other synthetic detergents.

However, when investigating the black light on the fiber or paper-mill products dyed with fluorescent whitening agent, it gives inconvenient impression where it emits blueness, but the fluorescent whitening agent receives misunderstanding that it is a harmful substance to be affiliated in the issue of environmental pollution or stability to the body. Therefore, the use of fluorescent whitening agent is increasing according to the increase of consumption of printing and writing paper.

The ozone is a strong oxidizing agent with high oxidation potential (2.08 eVolt)[6] and it creates quick oxidation reaction with organic and non-organic substances of various forms due to its unique molecular structure. The ozone is very unstable in the water and it self-decomposes due to cyclic chain reaction to go through middle products such as Hydroperoxide radical, Superoxide radical, and Ozonide radical to create $\mathrm{OH}$ radical with greater reactiveness. The organic matters that exist in the water can be decomposed through indirect reaction pathway that responds to $\mathrm{OH}$ radical and the direct reaction pathway that can directly remove the organic substances. The organic substance forms the ozonide due to the direct and indirect reaction to be decomposed with the aldehyde and simple organic substances to completely oxidize to water and carbon dioxide[7]. In the environmental aspect, the use of water resource is being expanded in many fields and the necessity of acquiring water resource has been increasing. When considering reality, the need for reusing wastewater is increasing in the qualitative aspect.

Therefore, this research evaluated the removal efficiency of the fluorescent whitening agent due to ozone oxidation based on the actual waste water containing fluorescent whitening agent by dispensing diaminostilbene disulfonic acid derivative fluorescent whitening agent as artificial sample by applying the ozone oxidation method based on the fluorescent whitening agent that influences the water quality of reused water.<smiles>Nc1ccc(C=C=Cc2ccc(N)cc2S(=O)(=O)O)c(S(=O)(=O)O)c1</smiles> 
Figure 1. Chemical structure of diaminostilbene disulfonic acid.

\section{Experiment}

\subsection{Materials}

The fluorescent whitening agent used in the experiment of this research is the fluorescent whitening agent of diaminostilbene disulfonic acid derivative mainly used in the paper-mill industry. It has been artificially produced for the artificial sample. The subject was the primary treated water to contain fluorescent whitening agent of diaminostilbene disulfonic acid derivate used in the process of Company M. The sample was collected from the primary chemical treatment water of the wastewater treatment. The fluorescent whitening agent of Diaminostilbene disulfonic acid derivative, which was artificially dispensed, has undiluted solution COD concentration of $217,500 \mathrm{mg} / \ell$, which is around 500 times higher than the concentration used in the process. The sample was dispensed for this experiment and the organic contaminant level of the water quality and physiochemical properties are shown in Table 1.

The actual wastewater used in this research is the wastewater from the primary chemical treatment water of Company M. The concentration of the wastewater is shown in Table 2.

Table 1. Characteristics of synthetic fluorescent whitening agent wastewater.

\begin{tabular}{|c|c|}
\hline Item & Concentration \\
\hline $\mathrm{COD}(\mathrm{mg} / \ell)$ & 433.0 \\
\hline $\mathrm{T}-\mathrm{N}(\mathrm{mg} / \ell)$ & 45.6 \\
\hline Color $(\mathrm{Pt} / \mathrm{Co})$ & 283 \\
\hline
\end{tabular}

Table 2. Characteristics of Paper \& Papermill Wastewater

\begin{tabular}{|c|c|}
\hline Item & Concentration \\
\hline $\mathrm{COD}(\mathrm{mg} / \ell)$ & 157.2 \\
\hline $\mathrm{T}-\mathrm{N}(\mathrm{mg} / \ell)$ & 13.5 \\
\hline Color $(\mathrm{Pt} / \mathrm{Co})$ & 40 \\
\hline
\end{tabular}

\subsection{Experiment Method}

The ozone generator used in this experiment was the ozone generator device of water electrode method. For the experiment the oxygen flow as set to $2 \mathrm{l} / \mathrm{min}$. Here, the concentration of the ozone was $166 \mathrm{~g}-\mathrm{O}_{3} / \mathrm{m}^{3}$ where the amount of ozone used in the experiment was set to $20.0 \mathrm{~g}-\mathrm{O}_{3} / \mathrm{hr}$. The ozone generator of water electrode method used in the experience is shown in Figure 2. It uses double dielectric. It forms water jacket that directly contacts the dielectric for direct cooling due to the coolant, and the

Anode on one side allows cathodes on the other side. The coolant is then applied as discharge electrode to induce cooling of the discharge heat due to direct contact for outstanding adherence of the coolant electrode and dielectric. Also, the discharge efficiency for ozone occurrence is outstanding to induce ozone discharge without particles. Therefore, electric discharge efficiency and cooling efficiency are increased to increase the change rate of the ozone, and by suppressing the ozone creation reduction 
factors due to heat reverse reaction, the high-concentrated ozone occurrence of high-purity state can be possible. Also, the reactor used for this experiment was composed of ozone oxidation reactor and treatment tank for stabilization of the residual ozone before and after ozone contact designed as structure to maximize the contact effect with the wastewater. The structure of the reactor can be seen in Figure 3. Wastewater inflow is moved to the ozone contact tank with zig-zag formation plate through the absorption pump in the treatment tank for strong oxidation through wastewater and ozone contact. It is then moved to the ozone oxidation device to process the residual ozone in the wastewater. Then, the gas non-reactive ozone is stabilized in the stabilizer with $\mathrm{MnO}_{2}$ catalyst to be discharged to the air. The wastewater completed of ozone oxidation reaction is moved to the treatment tank and then the process is repeated.

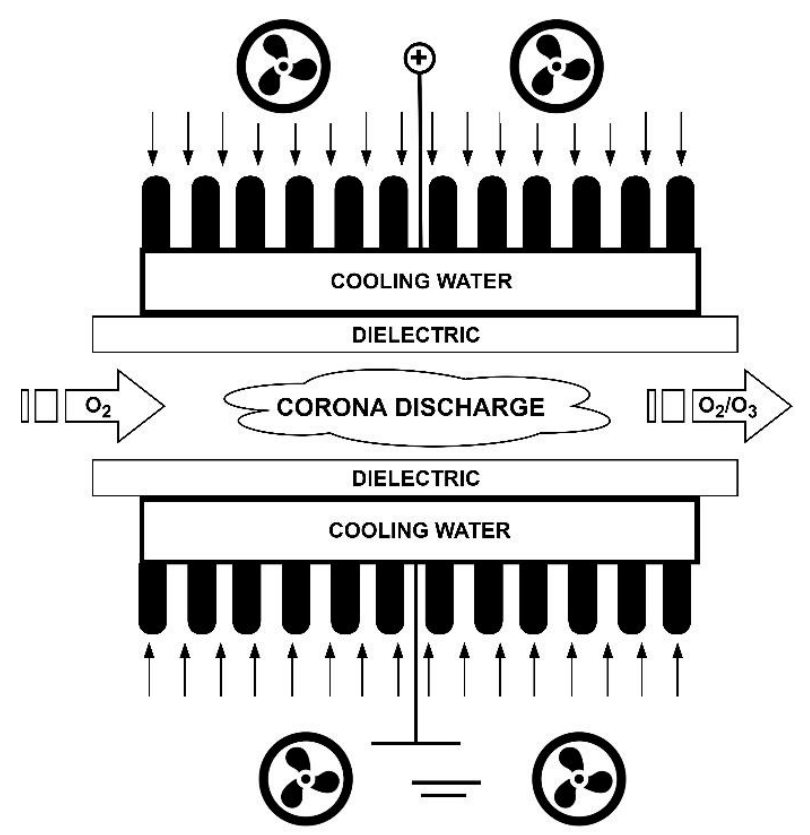

Figure 2. Schematic diagram of electric ozone discharge within water cooling.

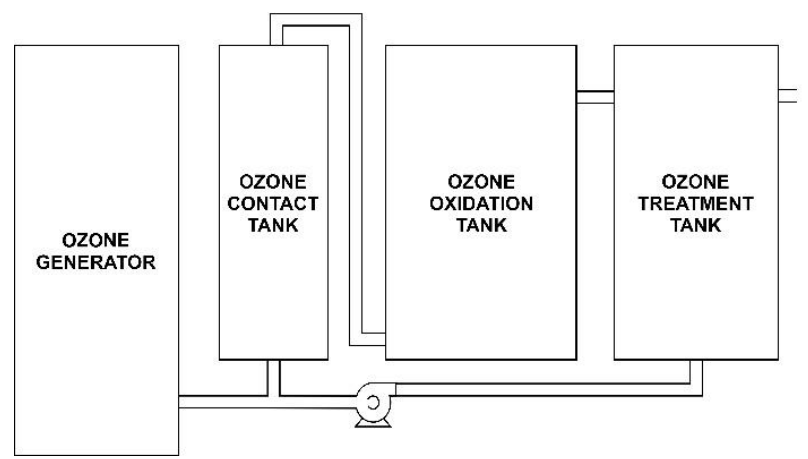

Figure 3. Schematic diagram of pilot plant ozone oxidation reactor.

\subsection{Analysis}

To evaluate the optimal ozone with treated fluorescent whitening dye and fluorescent whitening agent in the paper-mill wastewater, the experiment was done in the form of recirculating the wastewater. To evaluate the water quality after the contact between water quality and ozone, COD, T-N, chromaticity, 
and $\mathrm{UV}_{254}$ Scan were analyzed. The analysis method on the water quality was measured through Standard Methods[8].

\section{Result and discussion}

\subsection{Ozone Oxidation Experiment on the Sample of the Fluorescent Whitening Agent}

3.1.1 Absorption Wavelength Analysis by using Absorption Photometry of the Fluorescent Whitening Agent

The fluorescent whitening agent used in the composition process was used in this experience to increase the whiteness index of the paper in the process of manufacturing paper. The fluorescent whitening agent used in this experiment was the diaminostilnene disulfonic acid derivate known to be effective to increase whiteness of paper in the paper-mill factory and dye factory[9].

The dispensed fluorescent whitening agent was 50 times higher for the concentration compared to general agent. As a result of evaluating the organic contaminant, the concentration of the COD was 43.0 $\mathrm{mg} / \ell$, chromaticity was $283 \mathrm{Pt} / \mathrm{Co}$, and T-N was $45.6 \mathrm{mg} / \ell$. The result of executing experiment of the ozone oxidation for 0-90 minutes on the sample with only fluorescent whitening agent composed of diaminostilbene disulfonic is shown in Figure 4. The maximum absorption wavelength before oxidizing diaminostilbene disulfonic acid derivative showed maximum peak of $420 \mathrm{~nm}$. This reported 280-330 nm or $355 \mathrm{~nm}$ for the range of the diaminostilbene disulfonic acid derivative[10], but the reason this report was $420 \mathrm{~nm}$ higher than other studies was because of the diaminostilbene disulfonic acid whitening agent that was 500 times higher than the generally used amount where electrode property moved to the wavelength of the long wavelength zone[9]. Removal of the chromophore occurred from the starting point of the ozone oxidation where the maximum absorption wavelength was $380 \mathrm{~nm}$ in 5 minutes and below $350 \mathrm{~nm}$ in 30 minutes. Looking at this, it can be seen that the completion of the chromophore of the fluorescent whitening dye was completed within 30 minutes. Also, it was identified that the frequency of organic matters was diversified in 2-3 ABS zones of the organic matter wavelength due to the removal where the ozone oxidation became activated to go through various procedures of oxidation return to make decomposition of intermediate compounds possible. The removal of amino and sulfone inducing the combination of fiber and/or the fiber with the fluorescent whitening agent within 10 minutes of the ozone oxidation reaction time in the oxidation experiment of the diaminostilbene disulfonic acid derivative cause the main reaction, and it rapidly reacted with the ozone to create methyl and aldehyde[11,12]. From 30 minutes point, it led to the diaminostilbene sulfonic acid decomposition process to show removal rate of more than $50 \%$ in 90 minutes of the reaction time. The T-N concentration gradually increased between 5-10 minutes of the ozone oxidation time, and after 10 minutes the T-N concentration was stabilized. This is analyzed that the amino was probably the factor of increasing the concentration of T-N because the chromophore was removed due to ozone oxidation. However, it was identified in the analysis of chromaticity that the change was not significant. The chromaticity of the raw water being around 280 $\mathrm{Pt} / \mathrm{Co}$ was because the chromaticity increased in the light brown wavelength of benzene. Thus, fluorescent whitening dye absorbed the ultraviolet wavelength light to emit fluorescent, where there was barely any change of the wavelength in the visible region.

It took within 10 minutes to remove the optical whitening effect of the official sample fluorescent whitening agent. The ozone amount needed to remove the fluorescent whitening agent was $3.3 \mathrm{~g}-\mathrm{O}_{3} / \mathrm{hr}$. 


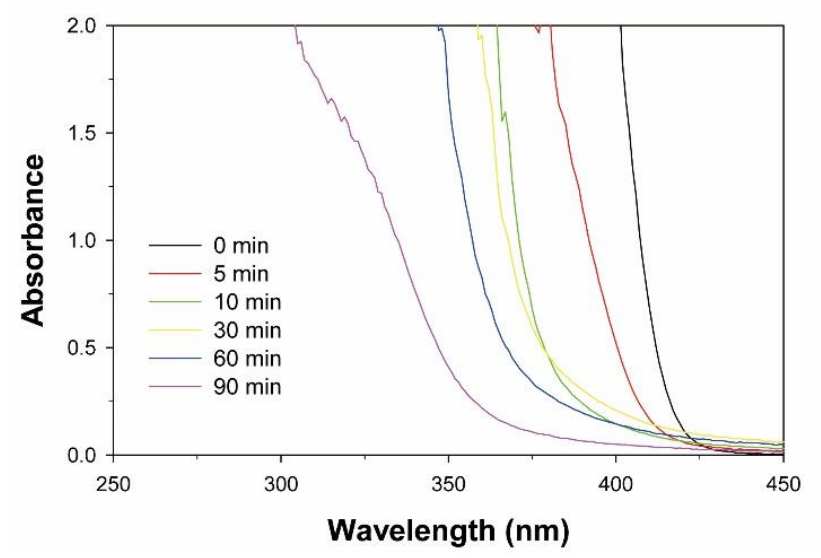

Figure 4. Effect of ozone oxidation of fluorescent whitening agents on $\mathrm{UV}_{254} \mathrm{Scan}$.

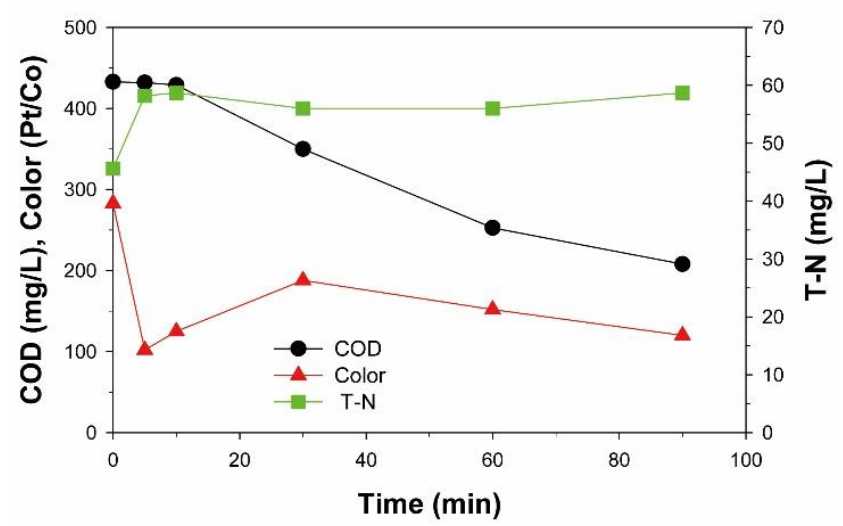

Figure 5. Effect of ozone oxidation of fluorescent whitening agents on COD, T-N and Color.

\subsection{Removal Experiment of Fluorescent Whitening agent in Paper-mill Wastewater}

3.2.1 Absorption Wavelength Analysis of Ozone Oxidation of the Fluorescent Whitening Agent in Papermill Wastewater

$\mathrm{UV}_{254}$ Scan analysis method is used as an analysis method of judging the conditions of whether or not a lot of aromatic chemical substance exists on the raw water. In this research that encountered errors to acquire water quality of wastewater in the biotreatment such as using aromatic chemical substance in dye and dispense, the diaminostilbene disulfonic acid fluorescent whitening dye was also an optical whitening agent made of aromatic chemical substance by oxidizing in reverse from the p-nitrotoluene. The used amount of fluorescent whitening agent used in the composition process of the paper manufacturing process showed below $7 \mathrm{mg} / \ell$ for the COD concentration as actual wastewater, but this study experimented by adding 10 times higher fluorescent whitening dye. The result is shown in Figure 6. As a result of analyzing the unique wavelength in the $\mathrm{UV}_{254}$ Scan due to the ozone oxidation, seeing that there was slight peak in $280 \mathrm{~nm}$ and $320 \mathrm{~nm}$, it was identified that there were organic chemical substances existing within the paper-mill wastewater in $280 \mathrm{~nm}$ and substances such as fluorescent whitening dye in $320 \mathrm{~nm}$.

In the first 30 minutes from the initial ozone oxidation, there was reduction in the two greatest wavelengths. This means that around $99 \%$ of the fluorescent whitening dye chromophore was removed and can be inferred that the optical whitening characteristic was removed. Also, it can be seen that it was 
changed to $254 \mathrm{~nm}$ zone where the reduction rate of the organic matter after 1 hour showed tendency of reducing to the ozone input.

The completion of decomposition of the fluorescent whitening dye on the actual wastewater was identified to be done after 30 minutes. Based on the $\mathrm{UV}_{254}$ Scan result, it was identified that 10.0g-O3/hr was needed for the ozone amount needed to remove the fluorescent whitening agent through ozone oxidation of actual wastewater.

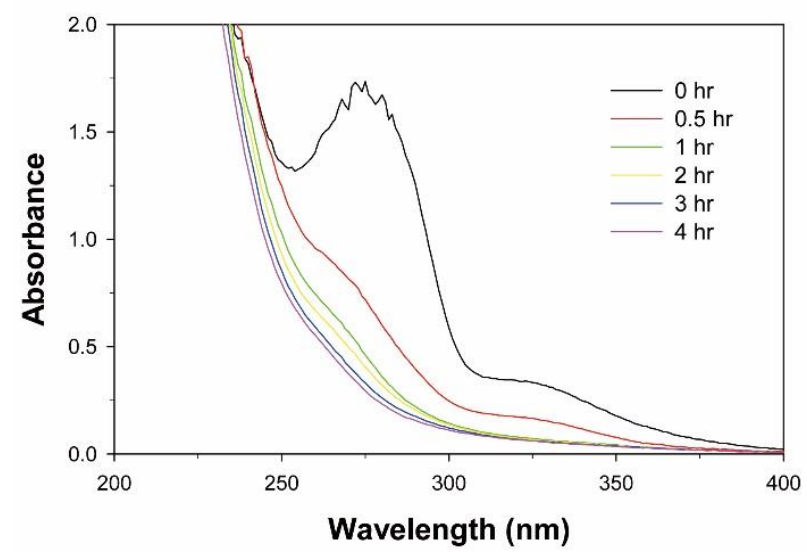

Figure 6. Effect of ozone oxidation of the paper and paper mill wastewater contained fluorescent whitening agents on $\mathrm{UV}_{254}$ scan.

3.2.2 Change of Organic Contaminant due to Ozone Oxidation of the Fluorescent Whitening Agent in the Paper-mill Wastewater

For the experiment, the primary chemical treatment water was collected from the paper-mill wastewater treatment facility, and the experiment was executed with 10 times higher concentration for the amount of the fluorescent whitening dye. The result is shown in Figure 7. The initial COD was around $150 \mathrm{mg} / \ell$ where in the first 10 minutes of ozone oxidation the destruction of amino acid of the chromophore occurred. In this serial process, the continuous process of oxidation reduction was judged to be intensively executed. After 2 hours of reaction, the oxidation speed relatively started to accelerate where the COD was $35 \mathrm{mg} / \ell$ at 240 minutes of reaction.

When reviewing the expectation effect of ozone oxidation of the wastewater of the paper-mill factory, the process of changing from non-degradable COD substance to biodegradable COD was circulated. Here, if the biotreatment is accompanied after 30 minutes of ozone oxidation due to the increase of the T$\mathrm{N}$ concentration, it is judged that there will be significant result in the organism replacement due to increase of nitrogen compound of biotreatment. Therefore, $10 \mathrm{~g}-\mathrm{O}_{3} / \mathrm{hr}$ of ozone input is needed during connection for biotreatment of the paper-mill wastewater, and the change of intermediate compound and change of T-N show the maximum value. 


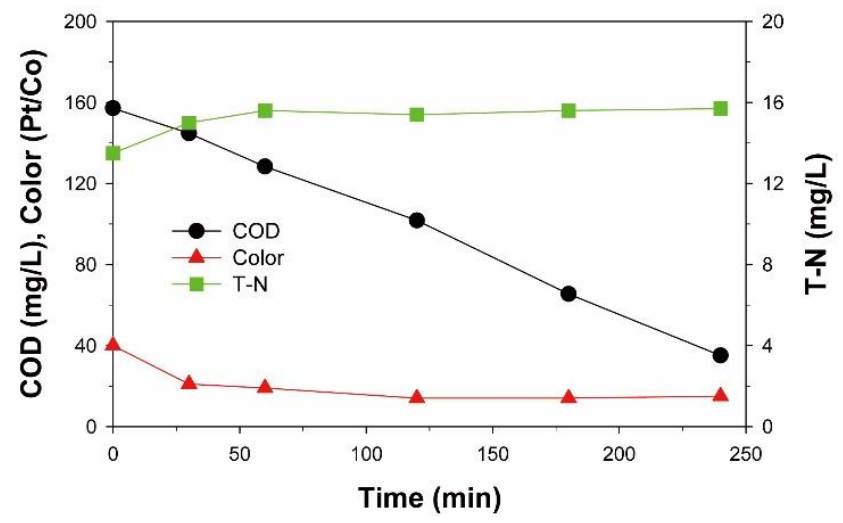

Figure 7. Effect of ozone oxidation of the paper and paper mill wastewater contained fluorescent whitening agents on COD, T-N and Color.

\section{Conclusion}

The experiment result for removal of fluorescent whitening agent by pretreatment ozone oxidation for MBR Process Application based on the actual wastewater $(157.2 \mathrm{mg} / \mathrm{l})$ containing fluorescent whitening agent and official sample (COD $433.0 \mathrm{mg} / \mathrm{l}$ ) made of diaminostilbene disulfonic acid derivative is as follows.

- It took within 10 minutes to remove the optical whitening effect of the diaminostilbene disulfonic acid fluorescent agent, the official sample (COD $433.0 \mathrm{mg} / \mathrm{l}$ ). Here, $3.3 \mathrm{~g}-\mathrm{O} 3 / \mathrm{hr}$ of ozone amount was needed for removal.

- Decomposition of fluorescent whitening dye on the actual wastewater (COD $157.2 \mathrm{mg} / \mathrm{l}$ ) appeared to be completed after 30 minutes as a result of the UV254 Scan. Based on this, the ozone amount needed to remove the fluorescent whitening agent through ozone oxidation of the actual wastewater was $10 \mathrm{~g}$ $\mathrm{O} 3 / \mathrm{hr}$.

- It was judged that 30 minutes for pretreatment ozone oxidation reaction was optimal during connection of the MBR process and Ozone Oxidation of the paper-mill wastewater. Here, $10 \mathrm{~g}-\mathrm{O} 3 / \mathrm{hr}$ of ozone input was needed. Also, Methyl, aldehyde, and acetic acid were created as the intermediate compounds that induce COD, and the TN concentration showed increase value of $10 \%$.

Acknowledgement: This subject is supported by Korea Ministry of Environment as "Global Top Project"(Project No.:2016002210001)

\section{References}

1. National Institute of Environmental Research Occurrence and treatment of factory wastewater; Seoul, South Korea, 2013;

2. Lim, G.B.; Lee, J.Y.; Kim, C.H.; Kim, S.Y.; Park, J.H. Study on the Factors Influencing the Fluorescence Index of Internal Fluorescent Whitening Agent. J. Korea Tech. Assoc. Pulp Pap. Ind. 2014, 46, 11-12. 
3. Kim, C.H.; Lee, J.Y.; Kim, B.H.; Choi, J.S.; Lim, G.B.; Kim, D.M. Study on the thermal fastness of fluorescent whitening agents. J. Korea Tech. Assoc. Pulp Pap. Ind. 2012, 44, 10-11.

4. Zhang, H.; He, Z.; Ni, Y.; Hu, H.; Zhou, Y. Using Optical Brightening Agents (OBA) for Improving the Optical Properties of HYP-Containing Paper Sheets. Pulp Pap. Canada 2009, 110, 20.

5. National Institute of Environmental Research Survey on Exposure of Fuorescent Bightener Agents by products; Seoul, South Korea, 2007;

6. Karat, I. Advanced Oxidation Processes for Removal of COD from Pulp and Paper Mill Effluents, Royal Institute of Technology in Stockholm, 2013.

7. Shin, H.S.; Lim, J.L. Improving Biodegradability of Naphthalene Refinery Process Wastewater by Ozonation. J. Korean Soc. Environ. Eng. 1993, 15, 478.

8. Rice, E..; Baird, R.B.; Eaton, A.D. Standard Method for Examination of Water and Wastewater; 19th ed.; APHA, AWWA and WPCF: Washington DC, USA, 1995;

9. Cho, B.U.; Won, J.M. Effect of PVAm Application for Fine Paper on Effectiveness of Optical Brightening Agent. J. Korea Tech. Assoc. Pulp Pap. Ind. 2016, 48, 24.

10. Chin, I.J.; Jang, C.S. Characterization of Epoxy Cure by Chromophore Labeling Technique. Polymer(Korea) 1990, 14, 285.

11. Kim, S.S.; Huh, M.W.; Han, M.H.; Yoon, J.H.; Cho, H.; Kim, D.K. A Study On The Decomposition Properties Of Disperse Dye Ozone Oxidation Treatment and The Optimum Treatment Condition(I). J. Korea Soc. Dye. Finish. 1996, 8, 45.

12. Peng, W.; Chen, Y.; Fan, S.; Zhang, F.; Zhang, G.; Fan, X. Use of 4, 4'-Dinitrostilbene-2, 2'Disulfonic Acid Wastewater As a Raw Material for Paramycin Production. Environ. Sci. Technol. 2010, 44, 9159. 